\title{
Study of the Osteoporotic Changes in Postmenopausal Women with Type-2 Diabetes Mellitus
}

\author{
Ayesha Jahan', Rokeya Begum², Khaled Bin Shamsuddin ${ }^{3}$ \\ ${ }^{1}$ Regional Public Administration Training Center (RPATC), New Eskaton, Dhaka. \\ ${ }^{2}$ National Institute of Nuclear Medicine and Allied Sciences (NINMAS), Shahbagh, Dhaka. \\ ${ }^{3}$ Central Drug Addiction Treatment Centre, Tejgaon, Dhaka.
}

Address for Correspondence: Dr. Ayesha Jahan, Medical Officer, Regional Public Administration Training Center (RPATC), 49, New Eskaton Road, Dhaka-1000, E-mail: ayesha.jahan01@yahoo.com, Tel: 01711281802.

\section{ABSTRACT}

Introduction: Osteoporosis and Diabetes Mellitus (DM) are common medical conditions in the society with an increasing prevalence in elderly people. Osteoporosis is more common in female than male and postmenopausal women are vulnerable to it.

Objective: The aim of this study was to verify the effect of type-2 diabetes mellitus on bone mineral density in postmenopausal women and, thereby, to evaluate the risk of osteoporosis in them.

Materials and Methods: This cross-sectional study was carried out at National institute of Nuclear Medicine and Allied Sciences (NINMAS), BSMMU campus, Shahbagh, Dhaka, over a period of one year. 175 postmenopausal women were enrolled as study subjects, among them 72 $(41.10 \%)$ were diabetic and rest $103(59.90 \%)$ were nondiabetic and they were assigned as Group-I and Group-II respectively. The bone mineral density (BMD) was measured by central DEXA device at lumbar spines and left femoral neck of each study subject.

Results: The mean $( \pm \mathrm{SD})$ ages of group-I and group-II were $58.79( \pm 8.06)$ and $58.27( \pm 8.39)$ respectively with an age range of 45 to 75 years in both cases. A total of $30(41.66 \%)$ patients in diabetic group (group-I) and $40(38.83 \%)$ patients in non-diabetic (group-II) had osteoporosis at lumbar spines. On the other hand, $40(56.94 \%)$ patients in group-I and 58 $(56.31 \%)$ patients in group-II had osteoporosis at femoral neck. The Odds Ratios of osteoporosis for lumbar spines and femoral. neck were 1.125 and 1.026 respectively. The differences of frequencies of osteoporosis between group-I and group-II were not statistically significant at any anatomical site and the association between osteoporosis and type-2 diabetes mellitus was not significant. According to Odds Ratio type-2 diabetes mellitus was not a risk factor for developing osteoporosis in postmenopausal women.

Conclusion: Postmenopausal women are prone to develop osteoporosis and type-2 diabetes mellitus may have adverse influence on osteoporosis, which was supported by few previous studies. This study could not establish any significant effect of type-2 diabetes mellitus on osteoporosis in postmenopausal women.

Key Words: Osteoporosis, Postmenopausal Women, Bone Mineral Density, Diabetes Mellitus

\section{INTRODUCTION}

Osteoporosis seems to be a silent epidemic that constitutes a great socio-economic problem with an impact on morbidity and mortality (1). Osteoporosis and diabetes mellitus (DM) are two of the most common chronic disorders of public health (2). Osteoporosis is a bone condition expressed by low bone mass, increased fragility, decreased bone quality and increased risk of fracture. It is the world's most prevalent metabolic disease of bone (1). Despite the adverse effect of osteoporosis it is often overlooked and under treated as clinically it remains silent until the manifestation of pain and fractures (3). Many individuals experience pain, disability and diminished quality of life due to osteoporosis (4).

The World Health organization (WHO) placed osteoporosis in the second position as a global health problem next to cardiovascular disease (5). The bone is a metabolically active organ and it undergoes continuous remodeling throughout life. This remodeling is important to maintain the structural integrity of the skeleton and to store calcium and phosphorous. Remodeling of bone begins early in foetal life and it is a two-part process consists of resorption and formation of new bone (6). The human skeleton is actually made up of two types of bones: the cortical bone and the trabecular bone. Cortical bone represents nearly $80 \%$ and trabecular bone represents only $20 \%$ of the skeletal mass. Cortical bone forms outer shell around every bone and has a slow turnover and a high resistance bending and torsion (7). Osteoporosis is an age related disease that affects women more often than male (3).

Menopause usually occurs between the ages 45 and 52 years, but it is not uncommon in the age 
after 40 or 54 years (8). Postmenopausal women experience both postmenopausal (type-I) and senile (type-II) osteoporosis. Postmenopausal osteoporosis is caused by oestrogen deficiency and senile osteoporosis was due to dysfunction of osteoblasts. At menopause women experience an accelerated transient phase which causes type-I osteoporosis and involves mainly trabecular bones. The slow, continuous bone loss in the elderly postmenopausal women causes both trabecular and cortical bone loss (9).

Diabetes mellitus (DM) is a metabolic disease characterizes hyperglycaemia that results in a long term damage, dysfunction and failure of various organs. Insulin plays the key role in glucose metabolism and it is necessary for the transport of glucose into the cells (10). Beside the role of insulin in glucose metabolism, insulin has anabolic effects on bone resulting in higher bone mineral density (BMD) (11).

Osteoporosis is a common disorder in the postmenopausal women. The risk of fracture following fall is enhanced by many folds in the presence of osteoporosis. Postmenopausal women with diabetes mellitus have higher risk of fall due to the common complications of diabetes resulting in fractures. In addition very few studies were conducted in developing countries regarding the risk of osteoporosis in postmenopausal women with type- 2 diabetes mellitus. The aim of this study was to verify the effect of type- 2 diabetes mellitus on bone mineral density in postmenopausal women and, thereby, to evaluate the risk of osteoporosis in them.

\section{MATERIALS AND METHODS}

This cross-sectional study was carried out at the National Institute of Nuclear Medicine and Allied Sciences (NINMAS), BSMMU campus, Shahbagh, Dhaka, over a period of twelve months from January 2012 to December 2012. The population of this study was the postmenopausal women who were referred to NINMAS for BMD test. A total of 175 diabetic and non-diabetic postmenopausal women were included in the study according to the selection criteria. Postmenopausal women were included in according to the selection criteria. Postmenopausal women with type- 2 diabetes mellitus and without diabetes with an age range from 45 to 75 years were included in this study. Postmenopausal women with type-1 diabetes mellitus, thyroid disorders, parathyroid disorders, CKD, COPD and surgical menopause were excluded from the study. The study was approved by the academic committee of NINMAS, Shahbagh, Dhaka. Written informed consent was obtained from each participant.

A total of 175 patients were enrolled in this study according the selection criteria after interviewing 211 postmenopausal women. The study subject was divided into two groups, 72 diabetic patients were in group-I (case) and 103 non-diabetic patients were in group-II (control). Their ages ranged from 45 to 75 years and they were divided into three age groups of 10 years segments, like as 46-55 years, 56-65 years and 66-75 years. Bone mineral density (BMD) was measured at lumbar spines and left femoral neck by Norland XR-46 densitometry central DEXA Device.

The study subjects were divided again into 4 groups according to $\mathrm{BMI}$, i.e. low $\mathrm{BMI}$ or underweight group $(\leq 18.5 \mathrm{Kg} / \mathrm{m} 2)$, normal BMI or normal weight group (18.5-24.9 Kg/m2), over weight group (25-29.9 Kg/m2) and obese group $(\geq 30 \mathrm{Kg} / \mathrm{m} 2)$.

Statistical analyses were done by SPSS version 18 for windows. Data presented on categorical form were analyzed using chi-square test and Fisher's exact test and continuous data were analyzed by ttest. In each analysis level of significance was 0.05 and $p$ value $<0.05$ was considered significant. Odds Ratios were calculated at $95 \%$ Confidence Interval (CI).

\section{OBSERVATION AND RESULTS}

Out of 175 postmenopausal women $72(41.10 \%)$ patients were in diabetic group or group-I and rest $103(58.9 \%)$ patients were in non-diabetic group or group-II (Table 1). 
Table 1: Distribution of the study population $(n=175)$

\begin{tabular}{lll}
\hline Group & $\begin{array}{l}\text { Number of } \\
\text { Patients }\end{array}$ & Percentage (\%) \\
\hline I (Diabetic) & 72 & 41.10 \\
\hline II (Non-diabetic) & 103 & 58.90 \\
\hline Total & $\mathbf{1 7 5}$ & $\mathbf{1 0 0}$ \\
\hline
\end{tabular}

In both groups the age ranged from 45 to 75 years. The mean $( \pm \mathrm{SD})$ ages were $58.79( \pm 8.06)$ and $58.27( \pm 8.39)$ in group-I and group-II respectively (Table 2).

Table 2: Distribution of mean ages in the study Population $(n=175)$

\begin{tabular}{cccccc}
\hline Group & $\begin{array}{c}\text { No. of } \\
\text { Patients }\end{array}$ & $\begin{array}{c}\text { Minimum } \\
\text { Age }(\mathrm{yrs})\end{array}$ & $\begin{array}{c}\text { Maximum } \\
\text { Age }(\mathrm{yrs})\end{array}$ & $\begin{array}{c}\text { Mean }( \pm S D) \\
\text { Age }(\mathrm{yrs})\end{array}$ & $\begin{array}{c}\mathbf{p} \\
\text { Value* }\end{array}$ \\
\hline I (Diabetic) & 72 & 45 & 75 & $58.79( \pm 8.06)$ & 0.683 \\
II (Nondiabetic) & 103 & 45 & 75 & $58.27( \pm 8.39)$ & \\
\hline
\end{tabular}

* $\mathrm{t}$ - test was done to measure the level of significance.

The mean $( \pm$ SD) BMI in Group-I was 26.27 $( \pm 5.53) \mathrm{Kg} / \mathrm{m}^{2}$ and in Group-II was $24.80( \pm 5.97)$ $\mathrm{Kg} / \mathrm{m}^{2}$ (Table 3).

Table 3: Distribution of BMI in the Study Population $(\mathbf{n}=\mathbf{1 7 5})$

\begin{tabular}{cccccc}
\hline Group & $\begin{array}{c}\text { No. of } \\
\text { Patients }\end{array}$ & $\begin{array}{c}\text { Minimum } \\
\text { BMI } \\
\left(\mathrm{kg} / \mathrm{m}^{2}\right)\end{array}$ & $\begin{array}{c}\text { Maximum } \\
\text { BMI } \\
\left(\mathrm{kg} / \mathrm{m}^{2}\right)\end{array}$ & $\begin{array}{c}\text { Mean }( \pm \text { SD }) \\
\text { BMI } \\
\left(\mathrm{kg} / \mathrm{m}^{2}\right)\end{array}$ & $\begin{array}{c}\mathbf{p} \\
\text { value* }\end{array}$ \\
\hline I (diabetic) & 72 & 15.40 & 43.56 & $26.27( \pm 5.53)$ & 0.067 \\
II (non-diabetc) & 103 & 14.80 & 40.44 & $24.80( \pm 4.97)$ & \\
\hline Total Population & 175 & 14.80 & 4.56 & $25.41( \pm 5.24)$ \\
\hline
\end{tabular}

* t- test was done to measure the level of significance.

Measuring the BMD of lumbar spines the mean $( \pm$ SD) T-scores of total population, group-I and group-II came $-2.02( \pm 1.11),-2.05( \pm 1.05)$ and $1.99( \pm 1.15)$ respectively. On the other hand the mean T-scores of left femoral neck of total study population, group-I and group-II were -2.58 $( \pm 1.15), \quad-2.61( \pm 1.12)$ and $-2.55 \quad( \pm 1.18)$ respectively (Table 4$)$.
Table 4: Distribution of $\mathrm{T}$-scores in the study population $(n=175)$

\begin{tabular}{|c|c|c|c|c|c|}
\hline Area & Group & $\begin{array}{c}\text { Minimum } \\
\text { T-Score }\end{array}$ & $\begin{array}{c}\text { Maximum } \\
\text { T-Score }\end{array}$ & $\begin{array}{c}\text { Mean }( \pm \text { SD) } \\
\text { T-Score }\end{array}$ & $\begin{array}{c}\text { p } \\
\text { value* }\end{array}$ \\
\hline Lumbar & $\begin{array}{l}\text { Total Study } \\
\text { Population }\end{array}$ & -4.52 & 3.56 & $-2.02( \pm 1.11)$ & \\
\hline Spines & $\begin{array}{l}\text { Group-I } \\
\text { Group-II }\end{array}$ & $\begin{array}{l}-4.52 \\
-4.01\end{array}$ & $\begin{array}{l}0.81 \\
3.56\end{array}$ & $\begin{array}{l}-2.05( \pm 1.05) \\
-1.99( \pm 1.15)\end{array}$ & 0.730 \\
\hline Femoral & $\begin{array}{l}\text { Total Study } \\
\text { Population }\end{array}$ & -4.92 & 1.04 & $-2.58( \pm 1.15)$ & \\
\hline Neck & $\begin{array}{l}\text { Group-I } \\
\text { Group-II }\end{array}$ & $\begin{array}{l}-4.60 \\
-4.92\end{array}$ & $\begin{array}{l}0.93 \\
1.04\end{array}$ & $\begin{array}{l}-2.61( \pm 1.12) \\
-2.55( \pm 1.18)\end{array}$ & 0.743 \\
\hline
\end{tabular}

In the total study population $35(20 \%)$ patients had normal BMD, $70(40 \%)$ patients had osteopenia and $70(40 \%)$ patients had osteoporosis at lumbar spines and $16(9.14 \%)$ patients had normal BMD, $60(34.2 \%)$ patients had osteopenia and 99 $(56.58 \%)$ patients osteoporosis at femoral neck.

At the lumbar spines $41.66 \%$ patients in diabetic group (group-I) and $38.83 \%$ patients in nondiabetic (group-II) had osteoporosis. $40.27 \%$ and $18.05 \%$ patients in group-I and $39.80 \%$ and $21.35 \%$ patients in group-II had osteopenia and normal BMD respectively. The differences of frequencies of osteoporosis, osteopenia and normal BMD between diabetic (group-I) and non-diabetic (group-II) were not statistically significant (Table 5).

Table 5: Comparison of BMD at lumbar spines between group-I and group-II

\begin{tabular}{ccccc}
\hline \multirow{2}{*}{ BMD Status } & \multicolumn{2}{c}{ Number of Patients } & \multirow{2}{*}{ Total } & \multirow{2}{*}{ p-value* } \\
\cline { 2 - 4 } & Group-I & Group-II & & \\
\hline Normal & $13(18.05 \%)$ & $22(21.35 \%)$ & $35(20.0 \%)$ & \\
Osteopenia & $29(40.27 \%)$ & $41(39.80 \%)$ & $70(40.0 \%)$ & 0.853 \\
Osteoporosis & $30(41.66 \%)$ & $40(38.83 \%)$ & $70(40.0 \%)$ & \\
\hline Total & $\mathbf{7 2}$ & $\mathbf{1 0 3}$ & $\mathbf{1 7 5}$ & \\
\hline
\end{tabular}

* Chi Square $\left(\chi^{2}\right)$ test was done to see the significance.

At the femoral Neck 56.94\%, 33.33\% and 9.72\% patients had osteoporosis, osteopenia and normal BMD respectively. On the contrary $56.31 \%$, $34.95 \%$ and $87.3 \%$ patients had osteoporosis, 
osteopenia and normal BMD respectively at femoral neck. The differences of frequencies of different BMD statuses were not statistically significant (Table 6).

Table 6: Comparison of BMD status at Femoral neck between group-I and group-II

\begin{tabular}{|c|c|c|c|c|}
\hline \multirow{2}{*}{ BMD status } & \multicolumn{2}{|c|}{ Number of Patients } & \multirow{2}{*}{ Total } & \multirow{2}{*}{ p-value* } \\
\hline & Group-I & Group-II & & \\
\hline Normal & $7(9.72 \%)$ & $9(8.73 \%)$ & $16(9.14 \%)$ & \\
\hline Osteopenia & $24(33.33 \%)$ & $36(34.95 \%)$ & $60(34.28 \%)$ & 0.961 \\
\hline Osteoporosis & $41(56.94 \%)$ & $58(56.31 \%)$ & $99(56.57 \%)$ & \\
\hline Total & 72 & 103 & 175 & \\
\hline
\end{tabular}

* Chi Square $\left(\chi^{2}\right)$ test was done to see the significance.

The comparison of frequencies of osteoporosis at lumbar spines and femoral neck between group-I and group- II showed no significant differences of occurrence of osteoporosis. (Figure 1).

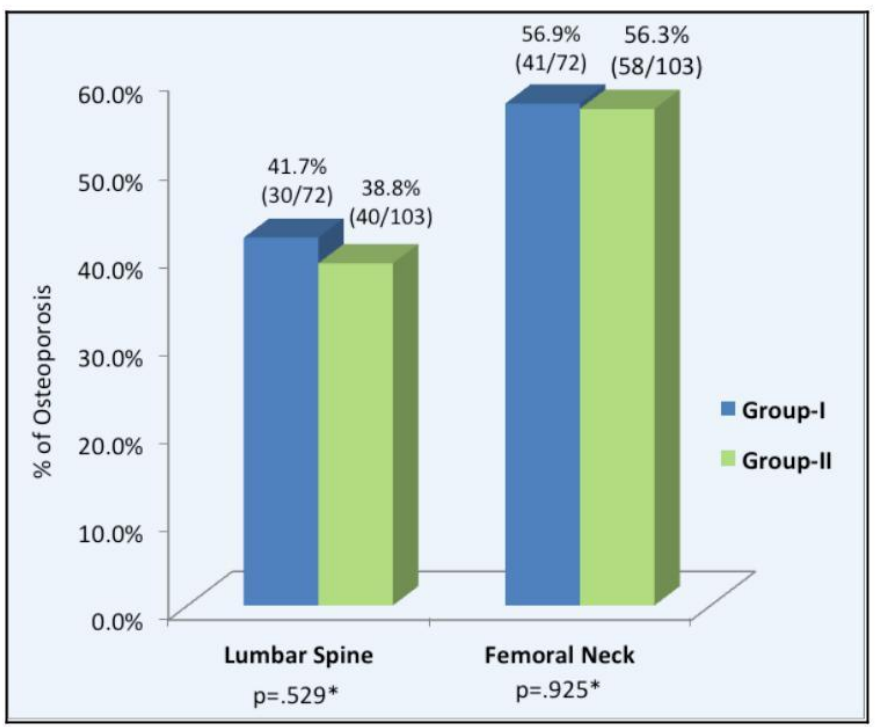

* Chi Square $\left(\chi^{2}\right)$ test was done to see the significance.

Figure1. Comparison of the frequencies of osteoporosis at lumbar spines and femoral neck between group-I and group-II.

The Odds of osteoporosis in diabetic (group-I) and non-diabetic (group-II) were 0.71 and 0.63 respectively at lumbar spines. The calculated Odds Ratios for lumbar spines osteoporosis was 1.125 (Table 7).

The Odds for osteoporosis in diabetic (group-I) was 1.322 and for non-diabetic (group-II) was 1.288 at femoral neck. The calculated Odds ratio was 1.026 for femoral neck osteoporosis (Table 8).
Table 7: Distribution of Odds and Odds Ratio in lumber spines in the total study population.

\begin{tabular}{|c|c|c|c|c|c|c|c|}
\hline \multirow[b]{2}{*}{ Exposure } & \multicolumn{2}{|c|}{ BMD Status } & \multirow[b]{2}{*}{ Total } & \multirow[b]{2}{*}{ Odds } & \multirow{2}{*}{$\begin{array}{l}\text { Odds } \\
\text { Ratio }\end{array}$} & \multicolumn{2}{|c|}{$95 \%$ CI for $\mathrm{OR}$} \\
\hline & $\begin{array}{r}\text { T-Score } \\
\leq-2.5^{*}\end{array}$ & $\begin{array}{l}\text { T-Score } \\
>-2.5^{* *}\end{array}$ & & & & Lower & Upper \\
\hline $\begin{array}{c}\text { Diabetes } \\
\text { Positive } \\
(\mathrm{Gr}-\mathrm{I})\end{array}$ & 42 & 30 & 72 & 0.71 & & & \\
\hline $\begin{array}{c}\text { Diabetes } \\
\text { Negative } \\
\text { (Gr-II) }\end{array}$ & 63 & 40 & 103 & 0.63 & 1.125 & 0.609 & 2.078 \\
\hline Total & 105 & 70 & 175 & & & & \\
\hline
\end{tabular}

$*$ T-Score $\leq-2.5$ : Positive for osteoporosis

$* * \mathrm{~T}$-Score $>-2.5$ : Negative for osteoporosis

Table 8: Distribution of Odds and Odds Ratio in femoral Neck in the total study population.

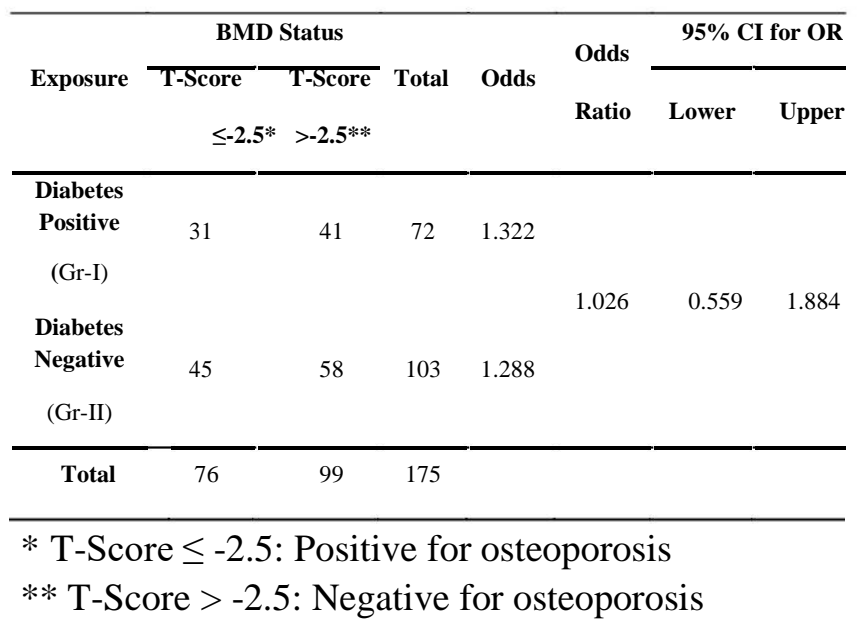

\section{DISCUSSION}

Osteoporosis and diabetes mellitus (DM) are two of the most common medical conditions and these have increase prevalence in elderly (1). The risk of fractures in osteoporosis increases many folds in presence of diabetes. Peripheral neuropathy, alteration in perception and involvement of eyes in diabetes mellitus make the patients of osteoporosis more prone to fall, hence vulnerable to fracture (2). In this study detailed histories and interviews of 211 postmenopausal women were taken, among which a total of 175 patients were enrolled who fulfilled the selection criteria. The ages of diabetic (group-I) and non-diabetic (group-II) groups were well matched. 
To evaluate and compare the bone mineral density (BMD) statuses in different ages, the total study population was divided into the three age groups. In order to estimate the effect BMI on bone mineral density (BMD) the study subjects were divided into four (4) BMI groups. The mean BMI of diabetic (group-I) showed that the maximum patients of these groups were overweight. On the other hand the mean BMI of group-II showed that maximum study population fell in normal weight group. But the difference of mean BMI between these two groups was not statistically significant $(\mathrm{p}=0.067)$ (TableIII). In this study bone mineral density (BMD) was measured by DXA at lumbar spines and left femoral neck of each patient. BMD was determined by $\mathrm{T}$ scores. The mean $( \pm \mathrm{SD}) \mathrm{T}$-scores of group-I and group-II were $-2.05( \pm 1.05)$ and $1.99( \pm 1.15)$ at lumbar spines respectively. The difference of $\mathrm{T}$ scores at lumbar spines between these two groups was not statistically significant. The mean $( \pm \mathrm{SD}) \mathrm{T}-$ scores of group-I at femoral neck were -2.61 $( \pm 1.12)$ and in group-II it was $-2.55( \pm 1.18)$. The difference of mean T-scores at femoral neck between these two groups was not statistically significant.

In group-I, $20(41.7 \%)$ patients and in group-II 40 $(38.8 \%)$ patients had osteoporosis at lumbar spines. Conversely, at the femoral neck $41(56.94 \%)$ patients in group-I and $58(56.31 \%)$ patients in group-II had osteoporosis. The differences of frequencies of osteoporosis between group-I and group-II were not statistically significant at either anatomical site with $\mathrm{p}$ values of 0.412 and 0.529 for lumbar spines and femoral neck respectively. So, no significant association between osteoporosis and type-2 diabetes mellitus could be found in this study. Similar findings were observed in several studies carried out in developed and developing countries. Isaia et al. Zhou et al (12) found that type-2 diabetes mellitus had negative effects on bone mineral density causing osteoporosis in postmenopausal women. In the present study, no relation between BMD (high or low) and type- 2 diabetes mellitus were observed; this might be true for this region (Southeast Asia) and might differ from other ethnic groups. (13), Maghbooli et al. (14), Sharifi et al. (15), Anaforoglu et al. (16) found similar findings in their studies and they dd not find any significant effects of type-2 diabetes mellitus on developing osteoporosis. But some studies showed reverse findings in their results. Studies conducted by Moghimi et al (1), Khalil et al. (2), Moreover, no such study was found in the other countries of Southeast Asia, like as, India, Pakistan and Nepal, to compare with. Furthermore, there are controversies regarding the BMD status in type- 2 diabetic patients, a few investigators found low BMD status in type-2 diabetic patients $(1,2,12,17)$ and some concluded with no difference $(13,14,15,16,18)$.

Comparing group-I and group-II according to age category it was found that osteoporosis and osteopenia were highest in frequencies in the oldest age categories (66-75 years) in both groups at both anatomical sites. The frequencies of osteoporosis were found more at femoral neck than at lumbar spines in both groups. In the total study population it was observed that $70(40 \%)$ patients had osteoporosis at lumbar spines. Conversely 99 $(56.6 \%)$ patients were osteoporotic at femoral neck in total study population. But the difference of frequencies of osteoporosis between these two sites was not statistically significant.

Odds Ratios for osteoporosis at lumbar spines and femoral neck for group-I and group-II were calculated to evaluate the risk of osteoporosis for type-2 diabetes mellitus. Compared to those who were non-diabetic (group-II), diabetic postmenopausal women (group-I) had 1.125 times higher odds to have osteoporosis at lumbar spines and 1.026 times higher Odds to have osteoporosis at femoral neck. The Odds Ratios were calculated at $95 \%$ confidence interval (CI) and it was found that type-2 diabetes mellitus was not a risk factor for developing either lumbar spines or femoral neck osteoporosis.

\section{CONCLUSION}

Awareness for prevention of impending osteoporosis in susceptible individuals as well as 
concerned physicians along with meticulous management of established osteoporosis can ensure a good quality of life of the patients. There are many studies advocating type-I diabetes mellitus as a risk factor for developing osteoporosis. But controversies still remain in case of the patients having type- 2 diabetes mellitus. Few international studies suggested that type-2 diabetes mellitus caused osteoporosis with an increasing frequency in postmenopausal women, but others could not establish this relationship. In the present study no significant difference of osteoporotic changes was observed between postmenopausal women with type- 2 diabetes mellitus and postmenopausal women without diabetes. The Odds Ratios also excluded type-2 diabetes mellitus as a risk factor for developing osteoporosis in postmenopausal women.

\section{REFERENCES}

1. Moghimi N, Rahimi E, Derakshan S and Farhadifar F. Osteoporosis in postmenopausal diabetic women; Prevalence and related factors. Iranian Journal of Nuclear Medicine, 2008; 16(2): 28-33.

2. Khalil N, Sutton-Tyrrell K, Strotmeyer E S, Greendale G A, Vagu M, Selzer F, Crandall C J and Cauley J A. Menopausal bone changes and incident fractures in diabetic women: a cohort study. Osteoporosis International, 2011; 22: 1367-1376.

3. Jacob-Kosmin D. Osteoporosis, 2011. Medscape Reference. Website: <http://emedicine.medscape. com/article330598overview > [Accessed 14 October 2012]

4. National Osteoporosis Foundation. A reference guide to osteoporosis reimbursement policy for healthcare professionals, 2011. Website: < www.nof.org/files /nof/public/content/resource/304/files3598.p>[Accesse d 12 December 2012]

5. Haldipur V. Boning up on osteoporosis. Indian Times, 2013. Website: $<$ http://health.indiatime. com/articleshow/329953.cms> [Accessed 23 March 2013]

6. Raisz L G. Physiology and Pathophysiology of bone remodeling. Clinical Chemistry, 1999; 45(8B): 13531358.

7. MEDES. Bone Physiology. Institute of Space Medicine and Physiology, 2005. Wedsite: <http://www.medes.fr/home-fr.html> [Accessed 19 December 2012]
8. Bhatla N, Clinical aspects of ovulation and menstruation. Jeffcoate's Principles of Gynaecology. 6th edn, Arnold Publishers, Canada, 2001: 88-93.

9. Sipos W, Pietschmann P, Rauner M, KerschanSchindl K and Patsch P. Pathophysiology of osteoporosis. Wiener Medizinische Wochenschrift, 2009; 159 (9-10): 230-234.

10. The Expert committee. Report of the expert committee on the diagnosis and classification of diabetes mellitus. Diabetes Care 2002; 24 (Supl.1): s5-s16.

11. Colledge $\mathrm{N} R$, Walker $\mathrm{B} \mathrm{R}$ and Ralston $\mathrm{S} \mathrm{H}$. Diabetes mellitus. Davidson's Principles and Practice of Medicine. 21st edn. Churchill Livingstone. Elsevier Ltd. London, 2010: 798-804.

12. Zhou Y, Li Y, Zhang D, Wang Jand Yang $\mathrm{H}$. Prevalence and predictors of osteopenia and osteoporosis in postmenopausal Chinese women with type-2 diabetes. Diabetes Research and Clinical Practice, 2010; 90: 261-269.

13. Isaia $G \mathrm{C}$, Ardissone $\mathrm{P}$, Di Stefano M, Ferrari D, Martina V, Porta M, Tagliabue M and Molinatti G

M. Bone Metaolism in type-2 diabetes mellitus. Acta Diabetology, 1999; 36: 35-38.

14. Maghbooli Z, Hossein-nezhad A, Khoshniat M, Abidi $\mathrm{H}$, Mohammadzadeh $\mathrm{N}$ and Larijani B. A study of bone mineral density in diabetes mellitus patients. Iranian Journal of Public Health, 2007; suppl.:37-44.

15. Sharifi $\mathrm{F}$, Ahmadimoghadam $\mathrm{N}$ and Mousavinasab $\mathrm{N}$. The relationship between type-2 diabetes mellitus and bone density in postmenopausal women. International Journal of Endocrinology and Metabolism, 2006; 4: 117-122.

16. Anaforoglu I, Nar-Demirer A, Bascil-Tutuncu $\mathrm{N}$ and Ertorer M E. Prevalence of osteoporosis and factors affecting bone mineral density among postmenopausal Turkish women with type 2 diabetes. Journal of Diabetes and Its Complications, 2009; 23: 12-17.

17. Al-Maatouq M A, El-Desouki M I, Othman S A, Matter E H, Babay Z A and Addar M. Prevalence of osteoporosis among postmenopausal females with diabetes mellitus. Saudi Medical Journal, Abstract, October 2004; 25 (10).

18. Cutrim D M S L, Pereira F A, Paula F J A and Foss M C. Lack of relationship between glycemic control and bone mineral density in type 2 diabetes mellitus. Brazilian Journal of Medical and Biological Research, 2007; 40: 221-227. 